\title{
Detection of Mycobacterium tuberculosis complex organisms in the stools of patients with pulmonary tuberculosis
}

Correspondence

Michel Drancourt

Michel.Drancourt@univmed.fr

Received 9 December 2008

Revised 16 April 2009

Accepted 22 April 2009

\author{
Amel El Khéchine, Mireille Henry, Didier Raoult and Michel Drancourt
}

URMITE CNRS-IRD, UMR 6236, Faculté de Médecine, IFR48, Université de la Méditerranée et Pôle de Maladies Infectieuses, Assistance Publique-Hôpitaux de Marseille, Marseille, France

\begin{abstract}
The laboratory diagnosis of pulmonary tuberculosis mainly relies on the detection of Mycobacterium tuberculosis complex (MTC) organisms in the sputum. In patients who do not give sputum, alternative respiratory tract specimens can be obtained only by invasive procedures. Based on the known survival of MTC organisms in the gastric fluid, we hypothesized that swallowed MTC organisms would be detectable in stool samples. We compared the presence of MTC organisms in respiratory tract specimens and stool specimens collected in parallel from the same patients. MTC was detected in cultures grown on egg-based medium after appropriate decontamination, by microscopic examination after Ziehl-Neelsen staining and by real-time PCR detection of IS6110 using internal controls. A case of pulmonary tuberculosis was defined by the presence of (i) clinical and radiological signs and symptoms suggestive of pulmonary tuberculosis, and (ii) culture of MTC organisms from at least one respiratory tract specimen or (iii) the presence of acid-fast bacilli in the sputum that were subsequently identified as MTC organisms by real-time PCR. The observation of 134 patients suspected to be suffering pulmonary tuberculosis led to the identification of 24 cases and 110 non-infected control patients. Cases and controls did not significantly differ with respect to sex but cases were significantly younger than controls. The sensitivity/specificity was $37.5 \% / 100 \%$ for the microscopic examination of stools, $54.2 \% / 100 \%$ for culturing and $100 \% / 97.3 \%$ for real-time PCR. The positive predicted value was $100 \%$, $100 \%$ and $88.9 \%$, respectively, and the negative predicted value was $88 \%, 90.9 \%$ and $100 \%$, respectively. In four patients, a stool specimen initially yielded the correct diagnosis of pulmonary tuberculosis before evaluation of the respiratory tract specimen confirmed the diagnosis. These data indicate that stools could be used in conjunction with sputum testing or as an alternative specimen upon which to base the diagnosis of pulmonary tuberculosis by molecular identification of acid-fast bacilli and culture. This non-invasive alternative procedure is of particular interest for patients who cannot expectorate.
\end{abstract}

\section{INTRODUCTION}

Pulmonary infection is the most prevalent form of tuberculosis (Saranchuk et al., 2007). Exposure to contact persons can cause secondary infection, and in some areas sustained high-level prevalence of this deadly infection (Johansen et al., 2002). The diagnosis of pulmonary tuberculosis currently relies upon the detection of Mycobacterium tuberculosis complex (MTC) organisms in sputum (Pfyffer, 2007). Some patients, however, are unable to produce sputum, including children (Oberhelman et al., 2006; Starke \& Correa, 1995), immunocompromised patients and patients with neurological impairment (Andresen, 2007). In these situations, alternative specimens obtained by invasive procedures include nasopharyngeal aspirates (Owens et al., 2007), gastric aspirates (Chierakul et al., 2003), respiratory tract secretions obtained by bronchoscopy (Ding et al., 2008) and intestinal fluid obtained by the string test (Vargas et al., 2005). The invasive procedures required to obtain the above-mentioned specimens are not comfortable for the patient and are potentially harmful.

The facts that swallowed MTC organisms can be detected in the gastric fluid and have been recently demonstrated to resist acid (Vandal et al., 2008) suggest that MTC organisms have the potential to survive the enteric tract and be eliminated in stools. However, few systematic evaluations of the utility of stool specimens for the diagnosis of pulmonary tuberculosis have been reported (Donald et al., 1996). We therefore examined stool 
specimens collected from patients in parallel with respiratory tract specimens for the presence of MTC organisms using a standardized protocol.

\section{METHODS}

Clinical specimens. Sputum specimens collected from patients suspected to be suffering pulmonary tuberculosis were routinely submitted to our laboratory for microbiological and molecular detection of MTC organisms. In addition, a stool specimen was collected into a sterile receptacle within $24 \mathrm{~h}$ of sputum collection. For cases in which several specimens were collected from a single patient, only the first sputum specimen and the first stool specimen were included in this study. The study was approved by a local Ethics Committee.

Microbiological procedures. Direct microscopic $(\times 100)$ examination was performed after Ziehl-Neelsen staining (Quick-TB kit, Réactifs RAL) of one drop of sputum or filtered stool specimen (see below). Respiratory tract specimens were digested and decontaminated by the NALC-NaOH method (Kent \& Kubica, 1985). A sample $(200 \mu \mathrm{l})$ of this suspension was inoculated into a BACTEC bottle (MycoF-sputa; Becton Dickinson), supplemented with $5 \%$ oleic acidalbumin-dextrose-catalase and PANTA (Becton Dickinson) and incubated in an automated BACTEC $9000 \mathrm{MB}$ system for two months.

Stool specimens were filtered using a faecal specimen filtration vial kit (Orion-Diagnostica-Fumouze-Division Diagnostics). The filtration vial contained buffer for sample dilution $(10 \mathrm{ml}$ Tris buffer, $0.05 \mathrm{M}$, $\mathrm{pH}$ 7.2). Its screw-on cap contained a spoon for sampling and a filter. We adapted this system by adding a macroporous compress, which has precise mesh openings and uniformly oriented fibres (Laboratoire Hydrex), to the vial cap so that the mycobacterial cells could not be trapped within the filter matrix. The attached spoon was used to place two spoonfuls of the faecal sample into the vial. The preparation was then shaken thoroughly in order to mix the sample with the buffer solution and the suspension was further filtered into a $50 \mathrm{ml}$ conical centrifuge tube. About $5 \mathrm{ml}$ of the stool filtrate was mixed with 3 vols $1 \%$ chlorhexidine digluconate (Sigma) (Best et al., 1990; Ferroni et al., 2006), vortexed for $15 \mathrm{~min}$ at room temperature, washed in PBS and centrifuged at $3000 \mathrm{~g}$ for $20 \mathrm{~min}$ at room temperature. The pellet was suspended in $1 \mathrm{ml}$ PBS, and $200 \mu \mathrm{l}$ of this specimen was inoculated onto a Löwenstein-Jensen slant (bioMérieux) and incubated at $37{ }^{\circ} \mathrm{C}$ for 2 months. The culture was examined daily for up to 1 week to check for any contamination, then twice weekly for 2 months to check for any growth of colonies. Colonies were identified as MTC organisms by Ziehl-Neelsen staining and molecular identification as described below.

DNA isolation. A filtered stool specimen or sputum sample $(250 \mu \mathrm{l})$ was inactivated by heating at $95^{\circ} \mathrm{C}$ for $1 \mathrm{~h}$, then transferred into a sterile screw-cap Eppendorf tube containing $0.3 \mathrm{~g}$ acid-washed glass beads (Sigma) and shaken in a Bio 101 FastPrep instrument (Qbiogene) at level 6.5 (full speed) for $45 \mathrm{~s}$. The supernatant was incubated overnight at $56{ }^{\circ} \mathrm{C}$ with $25 \mu \mathrm{l}$ proteinase $\mathrm{K}\left(20 \mathrm{mg} \mathrm{ml}^{-1}\right)$ and $180 \mu \mathrm{l} 1$ buffer from the Nucleospin Tissue Mini kit, according to the manufacturer's recommendations (Macherey-Nagel). After a second mechanical lysis, performed as described above, and a $15 \mathrm{~min}$ incubation at $100{ }^{\circ} \mathrm{C}$, total DNA was extracted using the NucleoSpin Tissue Mini kit, according to the manufacturer's recommendations. Extracted DNA was eluted into $100 \mu \mathrm{l}$ elution buffer and stored at $-20{ }^{\circ} \mathrm{C}$ until use. Sterile buffer $(250 \mu \mathrm{l})$ was run in parallel for each batch of DNA extractions as a negative control.

Molecular diagnosis. Real-time PCR amplification and detection of IS6110 was done using PCR primers and the detection probe reported in Table 1. The IS6110 system was tested with seven MTC species and the non-tuberculous species Mycobacterium avium, Mycobacterium fortuitum and Mycobacterium chelonae in order to ensure specificity. We compared the sensitivity of the real-time PCR detection in sputum and stool specimens by seeding five sputum and five stool specimens with $M$. tuberculosis H37Rv CIP 64.31. Real-time PCR was performed in an MX3000 system (Stratagene Europe) using the QuantiTect PCR mix (Qiagen), plus 5 pmol of each primer, 5 pmol probe and $5 \mu \mathrm{l}$ DNA in a final volume of $25 \mu \mathrm{l}$. PCR products for IS6110 and the internal control (Fig. 1) were detected in the same assay by use of the IS6110 probe labelled with FAM and an internal control probe labelled with VIC (FAM and VIC labels were from Applied Biosystems). The internal control plasmid was included in every PCR in order to check for the presence of PCR inhibitors. The concentration of the internal control was adjusted in order to obtain a $C_{\mathrm{t}}$ value of 27. Its composition (chimeric preparation of HPV18 and human albumin targets) was designed such that it would not interfere with any of the organisms found in stool specimens. A chimeric nucleotide fragment was constructed as previously described for quantification of the IS6110 gene copy number (Carcopino et al., 2006; Menard et al., 2008) (Fig. 2). A dilution series from $10^{7}$ to 10 copies of the quantification plasmid was run in parallel. The chimeric fragment contained the IS6110, ITS 1 (the internal transcribed spacer 1) and the internal standard target sequences reported in Table 1 . The ITS sequence was not evaluated in this study. M. tuberculosis H37Rv DNA was used as a positive control. Serial 10-fold dilutions of $M$.

Table 1. Internal standard and IS6110 probe and primer sequences used for real-time, standard PCRs and sequencing

\begin{tabular}{|llll|}
\hline Primer or probe & Target & \multicolumn{1}{c|}{ Sequence } & Amplicon size (bp) \\
\hline Standard PCR & & & 438 \\
PCR_IS6110_dir primer & IS6110 & $5^{\prime}$-TTCAGGTCGAGTACGCCTTC-3' & \\
PCR_IS6110_rev primer & & $5^{\prime}$-CGAACTCAAGGAGCACATCA-3' \\
Real-time PCR & & & 77 \\
Q.IS6110_dir primer & IS6110 & $5^{\prime}$-GTAGGCGTCGGTGCAAAAG-3' & \\
Q.IS6110_rev primer & & $5^{\prime}$-GGCTGTGGGATGCACACCT-3' & \\
IS6110_FAM probe & & 6FAM-ACGTAGGCGAACCCTGCC & \\
HPV18_dir primer & Internal control & $5^{\prime}$-AAAAACGACGATTTCACAACATAGC-3' \\
Alb_rev primer & & $5^{\prime}$-AAACTCATGGGAGCTGCTGGTTC-3' & \\
Albu_VIC probe & & VIC-CCTGTCATGCCCACACAAATCTCTCC &
\end{tabular}




\section{AAAAACGACGATTTCACAACATAGCTGGGCACTCTCGAGGCCAGTGCC}

ATTCGTGCTGCAACCGAGCACGACAGGAACGACTCCAACGACGCAGAGG

TTGCTGTCATCTCTTGTGGGCTGTAATCATCGTCTCGAGTTAAGAGTAATA

TTGCAAAACCTGTCATGCCCACACAAATCTCTCCCTGGCATTGTTGTCTT

TGCAGATGTCAGTGAAAGA GAACCAGCAGCTCCCATGAGTTT

Fig. 1. Internal standard sequence. Primer sequences for the internal control are boxed and in bold, and the probe is in bold and shaded grey. The boxed sequences in normal font correspond to Xhol sites that were introduced into the DNA for the detection of potential contamination.

tuberculosis $\mathrm{H} 37 \mathrm{Rv}$ were added to PCR-negative faecal samples in order to establish the detection limit of the PCR. The PCR programme consisted of $95{ }^{\circ} \mathrm{C}$ for $15 \mathrm{~min}$, followed by 45 cycles of $95{ }^{\circ} \mathrm{C}$ for $30 \mathrm{~s}$ and $60{ }^{\circ} \mathrm{C}$ for $1 \mathrm{~min}$. All PCRs were performed in duplicate. Results were expressed as the number of IS6110 copies in $5 \mu \mathrm{l}$ of DNA extracted from about $1 \mathrm{~g}$ of faeces or $250 \mu \mathrm{l}$ of sputum.

DNA sequencing. Standard PCR and sequencing reactions were performed for positive cases in order to confirm the specificity of the real-time PCR results. The PCR mixture contained $30.8 \mu \mathrm{l} \mathrm{H}_{2} \mathrm{O}, 5 \mu \mathrm{l}$ of $10 \times$ buffer (Qiagen), $2 \mu \mathrm{l} 25 \times \mathrm{MgCl}_{2}$ (Qiagen), $5 \mu \mathrm{l} 10 \times \mathrm{dNTPs}$, $0.2 \mu \mathrm{mol} 1^{-1}$ of each primer (Table 1 ), $5 \mu \mathrm{l}$ template DNA and $0.2 \mu \mathrm{l}$ Hotstart Taq (Qiagen). Negative controls consisted of PCR mix without target DNA. The positive control consisted of M. tuberculosis H37Rv DNA. PCR was performed using the following programme: 15 min enzyme activation at $95{ }^{\circ} \mathrm{C}$, followed by 49 cycles consisting of $95{ }^{\circ} \mathrm{C}$ for $30 \mathrm{~s}$, annealing at $60{ }^{\circ} \mathrm{C}$ for $45 \mathrm{~s}$ and elongation at $72{ }^{\circ} \mathrm{C}$

\section{GTAGGCGTCGGTGACAAAGGCCACGTAGGCGAACCCTGCCCAGGTCGAC}

ACATAGGTGAGGTCTGCTACCCACAGCCGTTCGCTCGAGGGTGGGGTGTGGTG

ITTGA GAACTGGATAGTGGTTGCGAGCATCAATGGATACGCTGCCGGCTAGCGGTGG CGTGTTCTTTGTGCAATATTCTTTGGTTTTTGTTGTGTTTGTAAGTGTCTAAGGGCGCAT

GGTGGATGCCTTGCTCGAG_AAAAACGACGATTTCACAACATAGCTGGGCACTC

TCGAGGCCAGTGCCATTCGTGCTGCAACCGAGCACGACAGGAACGACTCCAACG ACGCAGAGGTTGCTGTCATCTCTTGTGGGCTGTAATCATCGTCTCGAGTTAAGAG TAATATTGCAAAA CCTGTCATGCCCACACAAATCTCTCOCTGGCATTGTTGTCT TTGCAGATGTCAGTGAAAGAGAACCAGCAGCTCCCATGAGTTTGG

Fig. 2. Sequence of the chimeric nucleotide fragment (480 bp) inserted into the pCR II plasmid. The primers specific to the IS6110 gene of $M$. tuberculosis are in bold and shaded in light grey, while the probe is shaded in dark grey. The nucleotide sequence of the target on the ITS gene of pan-mycobacteria and M. tuberculosis is italicized and the primers are highlighted in black and white boxes. Probes for pan-mycobacteria are shaded in grey, with white text; probes for M. tuberculosis are shaded in grey, with black text. Primer sequences for the nucleotide sequence of the internal control are in normal font, underlined and in bold; the probe is boxed and in bold. The sequences in boxes and in normal font correspond to an Xhol site that was introduced for the detection of potential contamination. for $1 \mathrm{~min}$. A final elongation step was performed at $72{ }^{\circ} \mathrm{C}$ for $5 \mathrm{~min}$. Sequencing was done as previously described (Djelouadji et al., 2008).

Case definition. A case of pulmonary tuberculosis was defined by observation of (i) clinical and radiological signs and symptoms suggestive of pulmonary tuberculosis, and (ii) culture of MTC organisms from at least one respiratory tract specimen or (iii) the presence of acid-fast bacilli in the sputum, identified as MTC organisms by real-time PCR.

\section{RESULTS AND DISCUSSION}

A total of 134 first sputum and stool specimens were analysed for the presence of MTC organisms in 134 patients. Pulmonary tuberculosis was diagnosed in 24 patients, including 22 culture-positive patients and 2 patients with microscopic detection of acid-fast bacilli (AFB) identified as MTC by real-time PCR and sequencing (case group; mean age: $37 \pm 15$ years; sex-ratio male/ female: 15/9). Tuberculosis was excluded in 110 patients (control group; mean age: $52 \pm 18$ years; sex ratio male/ female: 87/23). Cases were younger than controls (chisquared $=0.064$ ) but did not differ with respect to sex. AFB were found in $11.2 \%$ sputum and in $6.7 \%$ stool specimens (Fig. 3). Molecular identification of AFB in stools was critical because Mycobacterium avium complex (Colebunders et al., 1990; Liesenfeld et al., 1995; Mavennyengwa \& Nziramasanga, 2003; Mazurek et al., 1997; Poropatich et al., 1987; Yajko et al., 1993), Mycobacterium florentium (Tortoli et al., 2005) and Mycobacterium gordonae (Liesenfeld et al., 1995) have been previously detected in patients' stools. Mycobacterium genavense DNA has been detected in colon biopsy samples of a few patients with colonic polyps and colonic cancer (Dumonceau et al., 1995) and in a few non-HIV, immunocompromised patients (de Lastours et al., 2008; Dumonceau et al., 1995). Also, MTC organisms can be detected in the stools of patients with digestive tuberculosis (Farid et al., 1999; Namisaki et al., 2004), a situation that was not addressed in this study. With respect to the

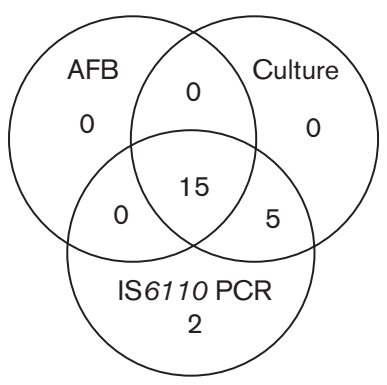

Sputum specimens

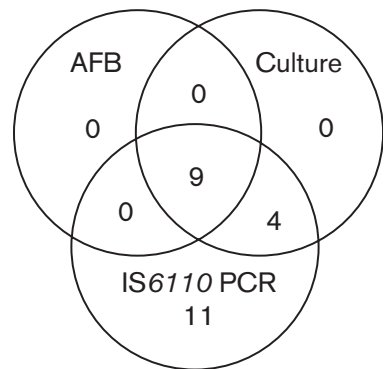

Stool specimens
Fig. 3. Distribution of $24 / 134$ patients with a final diagnosis of pulmonary tuberculosis by three diagnostic procedures: microscopic detection of AFB, culture and PCR-based detection of IS6110 of sputum and stool specimens. 
diagnosis of pulmonary tuberculosis, microscopic analysis of stools had a sensitivity of $37.5 \%$, which is slightly higher than the $34 \%$ reported for non-tuberculous mycobacteria (Morris et al., 1993). Specificity was $100 \%$, the negative predictive value (NPV) was $88 \%$ and the positive predictive value (PPV) was $100 \%$. In one patient, stool AFB permitted the diagnosis of pulmonary tuberculosis a few days before additional clinical specimens were shown to be positive. In three additional patients, including one HIV-infected patient and one kidney-transplant patient, diagnosis of pulmonary tuberculosis was provided exclusively by stool specimens.

MTC organisms grew in $14.9 \%$ sputum and $9.7 \%$ stool specimens (Fig. 3). Culture of stools had a sensitivity of $54.2 \%$, a specificity of $100 \%$, a PPV of $100 \%$ and an NPV of $90.9 \%$. Among protocols proposed for the decontamination of stools for the recovery of mycobacteria (Yajko et al., 1993), alkali is most widely used (Mavennyengwa \& Nziramasanga, 2003; Oberhelman et al., 2006). A recent study of paediatric patients in Peru found that culture of a gastric aspirate (15/15 cases) was superior to stool culture $(3 / 15)$ for the diagnosis of pulmonary tuberculosis (Oberhelman et al., 2006). The authors noted that culture of a larger volume of stool and improved decontamination/ concentration techniques could improve the sensitivity of stool culture (Oberhelman et al., 2006). We set up a new protocol for this purpose after a preliminary study in our laboratory indicated that chlorhexidine was more efficient than alkali (data not shown). This approach was previously reported for sputum decontamination in cystic fibrosis patients (Ferroni et al., 2006).

Real-time PCR detected MTC DNA in 28/134 (20.9\%) sputum and 27/134 (20.2\%) stool specimens (Fig. 3). Its sensitivity and specificity for stools were $100 \%$ and $97.3 \%$. The PPV was $88.9 \%$ and the NPV $100 \%$. The real-time PCR results were regarded as authentic because negative controls remained negative, the molecular technique used sealed capillary tubes known to limit the risk of molecular contamination, and the results of various techniques were in agreement. We further confirmed the specificity of the IS6110 target, as this PCR did not amplify the tested nontuberculous mycobacterial species. Sequencing performed for specimens found to be positive by real-time PCR confirmed the specificity of PCR for 24 patients in the presence of negative controls. Artificially spiked sputum and stool specimens gave a limit of detection of one organism per $25 \mu \mathrm{l}$ of PCR, with no significant difference in the $C_{\mathrm{t}}$ value between sputum and stool specimens. Incorporation of the internal control indicated that $2 / 134$ $(1.5 \%)$ sputum specimens and $3 / 134(2.2 \%)$ stool specimens were partially inhibited, a low value when compared with a reported $78 \%$ rate of inhibition using stool specimens (Reischl et al., 1998). This result indicated that the DNA extraction protocol we adopted in this study was highly efficient in removing PCR inhibitors from stools. We hypothesized that initial filtration and heat-inactivation steps contributed to this result. Moreover, we designed a DNA extraction protocol to optimize lysis of organisms with a thick and strong cell wall, including mycobacteria. This protocol uniquely comprises two mechanical lysis steps combined with strong enzymic lysis. $C_{\mathrm{t}}$ values varied from 21.7 to $38\left(7.7-9.12 \times 10^{5} \mathrm{M}\right.$. tuberculosis copies) for positive sputum specimens and from 22.8 to 37.5 (11.5$3.95 \times 10^{5}$ copies) for stool specimens. The number of IS6110 copies was higher in stools than in sputa in 11 cases; the copy number was higher in sputa than in stools in 6 cases and the other cases gave almost the same copy number in stools as in sputa. We further observed that the $C_{\mathrm{t}}$ values for 9 patients with positive AFB in stools were significantly lower than those for 15 patients without AFB in stools $(P=0.0008)$. Likewise, the $C_{\mathrm{t}}$ value for 15 patients with positive AFB in sputum was significantly lower than that for 9 patients without AFB in sputum $(P=0.0057)$.

There was a significant correlation between the delay of MTC growth and the $C_{\mathrm{t}}$ value for stool specimens $(P=0.0007)$ and a marginally significant correlation for sputum $(P=0.055)$. The fact that RT-PCR detected the presence of MTC DNA in otherwise culture-negative specimens has been previously reported (Soo et al., 2006). It may be due to the effectiveness of antituberculous drugs, which kill MTC organisms still excreting DNA, as documented in one patient in this series. Therefore, the detection of specific MTC DNA is not by itself a diagnosis of active pulmonary tuberculosis and it was not included in the case-definition in this report. Two patients were 7- and 14-year-old children, confirming the usefulness of stool analysis in paediatric patients. Another recent study in children also concluded the usefulness of PCR-based detection of IS6110 in stools but inhibition was not quantified and the sensitivity remained low, at 31-38\% (Wolf et al., 2008).

\section{Conclusion}

The data presented herein indicate that laboratory investigation of stools is favourable compared to that of respiratory tract specimens for the diagnosis of pulmonary tuberculosis, including in children, who often lack productive sputum, thus rendering the diagnosis of pulmonary tuberculosis more difficult. Children have been estimated to constitute up to $25 \%$ of all persons with tuberculosis in areas of high transmission (Nelson \& Wells, 2004), with an overall incidence of $9.6 / 100000$ personyears for patients $<20$ years of age in Taiwan (Chan et al., 2007). Patients with impaired mental status and immunocompromised patients, as herein reported, could also benefit from stool analyses for the diagnosis of pulmonary tuberculosis. Sensitivity, specificity and predictive values were not statistically different between respiratory tract specimens and stool specimens. Because these data were obtained in a prospective study performed during routine diagnosis in our laboratory, including more than 130 specimens, similar data should be obtained in other laboratories. 


\section{ACKNOWLEDGEMENTS}

This study was supported by l'Oeuvre anti-tuberculeuse des Bouches du Rhône, 2007 and URMITE. The authors acknowledge Professor Hervé Richet for his help with the statistical analyses. Authors' contributions: A.E.K. and M.H. performed the experiments, wrote the manuscript and contributed to drafting of the manuscript. D. R. and M.D. conceived the experimental design, provided support for the study and contributed to drafting of the manuscript. Conflict of interest: none.

\section{REFERENCES}

Andresen, D. (2007). Microbiological diagnostic procedures in respiratory infections: mycobacterial infections. Paediatr Respir Rev 8, 221-230.

Best, M., Sattar, S. A., Springthorpe, V. S. \& Kennedy, M. E. (1990). Efficacies of selected disinfectants against Mycobacterium tuberculosis. J Clin Microbiol 28, 2234-2239.

Carcopino, X., Henry, M., Benmoura, D., Fallabregues, A. S., Richet, H., Boubli, L. \& Tamalet, C. (2006). Determination of HPV type 16 and 18 viral load in cervical smears of women referred to colposcopy. J Med Virol 78, 1131-1140.

Chan, P. C., Huang, L. M., Wu, Y. C., Yang, H. L., Chang, I. S., Lu, C. Y., Lee, P. I., Lee, C. Y. \& Chang, L. Y. (2007). Tuberculosis in children and adolescents, Taiwan, 1996-2003. Emerg Infect Dis 13, 1361-1363.

Chierakul, N., Anantasetagoon, T., Chaiprasert, A. \& Tingtoy, N. (2003). Diagnostic value of gastric aspirate smear and polymerase chain reaction in smear-negative pulmonary tuberculosis. Respirology 8, 492-496.

Colebunders, R., Nembunzu, M., Portaels, F., Lusakumunu, K., Kapita, B. \& Piot, P. (1990). Isolation of mycobacteria from stools and intestinal biopsies from HIV seropositive and HIV seronegative patients with and without diarrhea in Kinshasa, Zaire. Preliminary results. Ann Soc Belg Med Trop 70, 303-309.

de Lastours, V., Guillemain, R., Mainardi, J. L., Aubert, A., Chevalier, P., Lefort, A. \& Podglajen, I. (2008). Early diagnosis of disseminated Mycobacterium genavense infection. Emerg Infect Dis 14, 346-347.

Ding, H., Ma, Y., Rao, X., Jiao, A. \& Liu, X. (2008). The role of flexible bronchoscopy in pediatric pulmonary tuberculosis. J Trop Pediatr 54, 423.

Djelouadji, Z., Raoult, D., Daffé, M. \& Drancourt, M. (2008). A singlestep sequencing method for the identification of Mycobacterium tuberculosis complex species. PLoS Negl Trop Dis 2, e253.

Donald, P. R., Schaaf, H. S., Gie, R. P., Beyers, N., Sirgel, F. A. \& Venter, A. (1996). Stool microscopy and culture to assist the diagnosis of pulmonary tuberculosis in childhood. J Trop Pediatr 42, 311-312.

Dumonceau, J. M., Fonteyne, P. A., Realini, L., Van Gossum, A., Van Vooren, J. P. \& Portaels, F. (1995). Species-specific Mycobacterium genavense DNA in intestinal tissues of individuals not infected with human immunodeficiency virus. J Clin Microbiol 33, 2514-2515.

Farid, Z., Kamal, M., Karam, M., Mousa, M., Sultan, Y. \& Antosek, L. E. (1999). Extra-pulmonary tuberculosis in patients with fever of unknown origin: clinical features and diagnosis. J Egypt Public Health Assoc 74, 473-484.

Ferroni, A., Vu-Thien, H., Lanotte, P., Le Bourgeois, M., SermetGaudelus, I., Fauroux, B., Marchand, S., Varaigne, F., Berche, P. \& other authors (2006). Value of the chlorhexidine decontamination method for recovery of nontuberculous mycobacteria from sputum samples of patients with cystic fibrosis. J Clin Microbiol 44, 2237-2239.

Johansen, I. S., Thomsen, V. O., Johansen, A., Andersen, P. \& Lundgren, B. (2002). Evaluation of a new commercial assay for diagnosis of pulmonary and nonpulmonary tuberculosis. Eur J Clin Microbiol Infect Dis 21, 455-460.

Kent, P. T. \& Kubica, G. P. (1985). A Guide for the Level III Laboratory. Atlanta, GA: Centers for Disease Control and Prevention.

Liesenfeld, O., Schneider, T., Schmidt, W., Sandforth, J., Weinke, T., Zeitz, M., Riecken, E. O. \& Ullrich, R. (1995). Culture of intestinal biopsy specimens and stool culture for detection of bacterial enteropathogens in patients infected with human immunodeficiency virus. The Berlin Diarrhea/Wasting Syndrome Study Group. J Clin Microbiol 33, 745-747.

Mavennyengwa, R. T. \& Nziramasanga, P. (2003). Use of culture methods for recovery of atypical mycobacteria from stools of AIDS patients. Cent Afr J Med 49, 31-37.

Mazurek, G. H., Chin, D. P., Hartman, S., Reddy, V., Horsburgh, C. R., Jr, Green, T. A., Yajko, D. M., Hopewell, P. C., Reingold, A. L. \& Crawford, J. T. (1997). Genetic similarity among Mycobacterium avium isolates from blood, stool, and sputum of persons with AIDS. J Infect Dis 176, 976-983.

Menard, J. P., Fenollar, F., Henry, M., Bretelle, F. \& Raoult, D. (2008). Molecular quantification of Gardnerella vaginalis and Atopobium vaginae loads to predict bacterial vaginosis. Clin Infect Dis 47, 33-43.

Morris, A., Reller, L. B., Salfinger, M., Jackson, K., Sievers, A. \& Dwyer, B. (1993). Mycobacteria in stool specimens: the nonvalue of smears for predicting culture results. J Clin Microbiol 31, 1385-1387. Namisaki, T., Yoshiji, H., Fujimoto, M., Kojima, H., Yanase, K., Kitade, M., Ikenaka, Y., Toyohara, M., Yamao, J. \& other authors (2004). Two cases of colonic tuberculosis presenting with massive melena. Int J Clin Pract 58, 1162-1164.

Nelson, L. J. \& Wells, C. D. (2004). Tuberculosis in children: considerations for children from developing countries. Semin Pediatr Infect Dis 15, 150-154.

Oberhelman, R. A., Soto-Castellares, G., Caviedes, L., Castillo, M. E., Kissinger, P., Moore, D. A., Evans, C. \& Gilman, R. H. (2006). Improved recovery of Mycobacterium tuberculosis from children using the microscopic observation drug susceptibility method. Pediatrics 118, e100-e106.

Owens, S., Abdel-Rahman, I. E., Balyejusa, S., Musoke, P., Cooke, R. P., Parry, C. M. \& Coulter, J. B. (2007). Nasopharyngeal aspiration for diagnosis of pulmonary tuberculosis. Arch Dis Child 92, 693-696.

Pfyffer, G. (2007). Mycobacterium: General Characteristics, Laboratory Detection and Staining Procedures, 9th edn, pp. 543-572. Edited by P. R. Murray, E. J. Barron, J. H. Jorgensen, M. L. Landry \& M. A. Pfaller. Washington DC: American Society for Microbiology.

Poropatich, C. O., Labriola, A. M. \& Tuazon, C. U. (1987). Acid-fast smear and culture of respiratory secretions, bone marrow, and stools as predictors of disseminated Mycobacterium avium complex infection. J Clin Microbiol 25, 929-930.

Reischl, U., Lehn, N., Wolf, H. \& Naumann, L. (1998). Clinical evaluation of the automated COBAS AMPLICOR MTB assay for testing respiratory and nonrespiratory specimens. J Clin Microbiol 36, 2853-2860.

Saranchuk, P., Boulle, A., Hilderbrand, K., Coetzee, D., Bedelu, M., van Cutsem, G. \& Meintjes, G. (2007). Evaluation of a diagnostic algorithm for smear-negative pulmonary tuberculosis in HIV-infected adults. S Afr Med J 97, 517-523.

Soo, P. C., Horng, Y. T., Hsueh, P. R., Shen, B. J., Wang, J. Y., Tu, H. H., Wei, J. R., Hsieh, S. C., Huang, C. C. \& Lai, H. C. (2006). Direct and simultaneous identification of Mycobacterium tuberculosis complex (MTBC) and Mycobacterium tuberculosis (MTB) by rapid multiplex nested PCR-ICT assay. J Microbiol Methods 66, 440-448.

Starke, J. R. \& Correa, A. G. (1995). Management of mycobacterial infection and disease in children. Pediatr Infect Dis J 14, 455-469. 
Tortoli, E., Rindi, L., Goh, K. S., Katila, M. L., Mariottini, A., Mattei, R., Mazzarelli, G., Suomalainen, S., Torkko, P. \& Rastogi, N. (2005). Mycobacterium florentinum sp. nov., isolated from humans. Int J Syst Evol Microbiol 55, 1101-1106.

Vandal, O. H., Pierini, L. M., Schnappinger, D., Nathan, C. F. \& Ehrt, S. (2008). A membrane protein preserves intrabacterial $\mathrm{pH}$ in intraphagosomal Mycobacterium tuberculosis. Nat Med 14, 849-854.

Vargas, D., Garcia, L., Gilman, R. H., Evans, C., Ticona, E., Navincopa, M., Luo, R. F., Caviedes, L., Hong, C. \& other authors (2005). Diagnosis of sputum-scarce HIV-associated pulmonary tuberculosis in Lima, Peru. Lancet 365, 150-152.
Wolf, H., Mendez, M., Gilman, R. H., Sheen, P., Soto, G., Velarde, A. K., Zimic, M., Escombe, A. R., Montenegro, S. \& other authors (2008). Diagnosis of pediatric pulmonary tuberculosis by stool PCR. Am J Trop Med Hyg 79, 893-898.

Yajko, D. M., Nassos, P. S., Sanders, C. A., Gonzalez, P. C., Reingold, A. L., Horsburgh, C. R., Jr, Hopewell, P. C., Chin, D. P. \& Hadley, W. K. (1993). Comparison of four decontamination methods for recovery of Mycobacterium avium complex from stools. J Clin Microbiol 31, 302306.

Edited by: M. Daffé 